\title{
Having a stroke increased the risk of developing dementia in older people
}

Ivan CS, Seshadri S, Beiser A, et al. Dementia after stroke: the Framingham Study. Stroke 2004;35:1264-8.

In older people, does having a stroke increase the risk of developing dementia?

METHODS

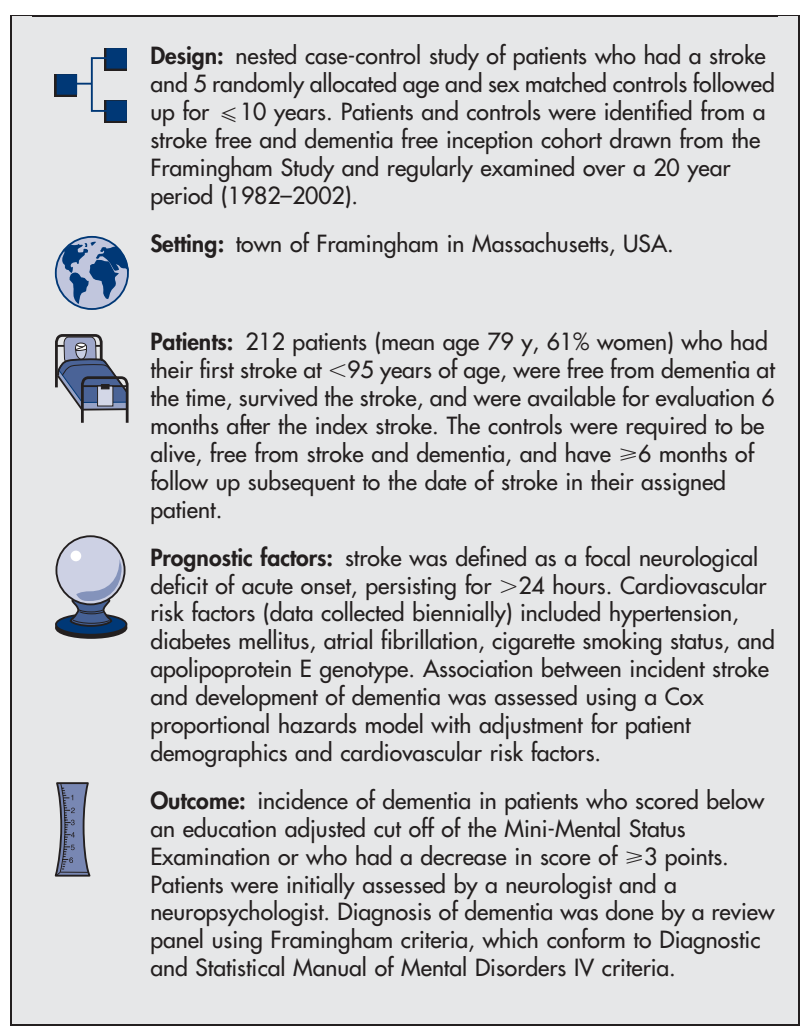

\section{MAIN RESULTS}

The 10 year incidence of dementia was greater among patients who had had a stroke than among matched controls (19\% v $11 \%$, For correspondence: Dr P A Wolf, Boston University School of Medicine, Boston, MA, USA. pawolf@bu.edu

Sources of funding: National Institutes of Health; National Institute of Ageing; National Institute of Neurological Disorders and Stroke; and Boston University Alzheimer's Disease Center. $\mathrm{p}<0.001$ ). Overall, the presence of baseline stroke doubled the risk of dementia after adjustment for age, sex, and educational status (table). Additional adjustment for apolipoprotein E genotype status, stroke location, stroke type, presence of a second stroke, and individual stroke risk factors did not substantially alter the risk (table).

\section{CONCLUSION}

In older people, having a stroke increased the risk of developing dementia.

\section{Commentary}

A Ithough previous studies have examined the risk of developing dementia after stroke, the study by lvan et al is unique in its use of a community based inception cohort free of dementia or stroke. Biennial assessment of the cohort is also a notable strength. The study design minimised the possibility of including individuals with dementia before their index stroke, and the use of a community based cohort ensured the inclusion of patients whose stroke care did not include a hospital stay. Overall the findings are more optimistic than those of previous studies, but they do confirm that stroke is a significant risk factor for developing dementia.

A previous study indicated a 9 fold increase in the risk of developing dementia in the year after stroke, ${ }^{1}$ but the findings of Ivan et al indicate that the risk of early dementia is not as great as was previously thought. The difference in the findings of Ivan et al and those of earlier studies could be accounted for by the exclusion of patients with pre-existing dementia (before stroke) and the stricter criteria for diagnosing dementia.

The findings of Ivan et al are relevant to nurses working with older people in settings ranging from primary care to acute care. They reinforce the importance of stroke prevention measures, not only in reducing the deleterious effects of stroke itself but also in decreasing the incidence of dementia. The $19 \%$ incidence of dementia within 10 years of the index stroke also reinforces the value of regular long term screening after stroke to detect signs of dementia onset and initiate timely, interventions when necessary. Furthermore, clients who are already aware of the increased risk of dementia will probably find it reassuring to know that most people who have a stroke remain dementia free at 10 years.

Jackie Bridges, RN, RHV, PhD St Bartholomew School of Nursing \& Midwifery, City University London, UK 1 Kokmen E, Whisnant JP, O'Fallon WM, et al. Neurology 1996;46:154-9.

Association between baseline stroke and incidence of dementia in older people*

\begin{tabular}{|c|c|c|}
\hline Variable adjusted for & $\begin{array}{l}\text { Number of patients with } \\
\text { dementia (N) }\end{array}$ & Hazard ratio $(95 \% \mathrm{Cl})$ \\
\hline None: crude risk & $158(1272)$ & $2.2(1.5$ to 3.1$)$ \\
\hline Age, sex, and education & 153 (1239) & $2.0(1.4$ to 2.9$)$ \\
\hline Apolipoprotein $E \in 4$ genotype status $\dagger$ & $92(801)$ & $2.8(1.7$ to 4.4$)$ \\
\hline Stroke type (hemisphere, $\mathrm{ABI} / \mathrm{CE}) \dagger$ & 153 (1239) & $2.0(1.4$ to 2.9$)$ \\
\hline Second stroke† & 153 (1239) & $2.0(1.4$ to 2.9$)$ \\
\hline $\begin{array}{l}\text { Second stroke and stroke risk factors (hypertension, diabetes, } \\
\text { atrial fibrillation, current smoking) } \dagger\end{array}$ & $114(844)$ & $2.4(1.6$ to 3.7$)$ \\
\hline
\end{tabular}

${ }^{*} \mathrm{~N}=$ total number of cases plus controls with information available on the status of each vascular risk factor; $\mathrm{ABI}=$ atherothrombotic brain infarct; $\mathrm{CE}=$ cardioembolic. $\mathrm{Cl}$ defined in glossary.

†Adjusted for age, sex, and education in addition to listed variable. 